\title{
A New Look on an Old Issue: Comprehensive Review of Neurotransmitter Studies in Cerebrospinal Fluid of Patients with Schizophrenia and Antipsychotic Effect on Monoamine's Metabolism
}

\author{
Matthieu Gasnier ${ }^{1}$, Pierre Ellul ${ }^{2}$, Marion Plaze ${ }^{3}$, Pierre Abdel Ahad $^{3}$ \\ ${ }^{1}$ Department of Psychiatry, MOODS Team, Paris Saclay University, Bicetre Hospital, AP-HP, ${ }^{2}$ Department of Child and Adolescent Psychiatry, \\ Robert Debré Hospital, AP-HP, ${ }^{3}$ Department of Psychiatry, Service Hospitalo Universitaire, Sainte Anne Hospital, Paris, France
}

\begin{abstract}
Neurotransmitters metabolism has a key role in the physiopathology of schizophrenia as demonstrated by studies measuring monoamine metabolites in patient's cerebrospinal fluid (CSF) since the beginning of the antipsychotic use. This comprehensive review aims to understand the anomalies of CSF monoamines in schizophrenia and their correlation with clinical and paraclinical features. We also review the influence of antipsychotic treatment on CSF monoamines and discuss the connection with metabolic and inflammatory processes. Studies comparing CSF homovanillic acid (HVA) levels between patients and controls are miscellaneous, due to the heterogeneity of samples studies. However, low HVA is associated with more positive symptoms and a poorer outcome and negatively correlated with brain ventricle size. Based on humans and animals' studies, antipsychotic treatments increase HVA during the first week of administration and decrease progressively over the time with a fall-off after withdrawal. 5-hydroxyindolacetic acetic acid levels do not seem to be different in the patient's CSF compared to controls. Considering metabolic co-factors of neurotransmitters synthesis, there is evidence supporting an increase of kynurenic acid in the CSF of patients with schizophrenia. Few studies explore folate metabolism in CSF. Literature also emphasizes the relationship between folate metabolism, inflammation and monoamine's metabolism. Those results suggest that the CSF monoamines could be correlated with schizophrenia symptoms and treatment outcome. However, further studies, exploring the role of CSF monoamines as biomarkers of disease severity and response to treatment are needed. They should assess the antipsychotic prescription, inflammatory markers and folate metabolism as potential confounding factors.
\end{abstract}

KEY WORDS: Neurotransmitters; Schizophrenia; Cerebrospinal fluid; Inflammation; Antipsychotic drug.

\section{INTRODUCTION}

Schizophrenia affects $1 \%$ of the population and leads to severe clinical conditions [1]. Treatment resistance occurs in almost $30 \%$ of patients and is responsible for more severe and chronic impairment [2]. In the 50's, the discovery of the key role of dopamine in the physiopathology of schizophrenia was demonstrated by the efficacy of

Received: September 24, 2020 / Revised: November 30, 2020 Accepted: December 28, 2020

Address for correspondence: Matthieu Gasnier Department of Psychiatry, MOODS Team, Paris Saclay University, Bicetre Hospital, AP-HP, 78 Rue du Général Leclerc, 94270 Le Kremlin-Bicêtre, Paris, France

E-mail: matthieu.gasnier@aphp.fr

ORCID: https://orcid.org/0000-0003-4887-4025 antipsychotic (i.e., D2 receptor-blocker) treatment [3]. Schizophrenia is a neurodevelopmental disease of unclear etiology for whom onset is related to a complex combination of genetic and environmental factors [4,5]. Among genetic factors, the latest Genome Wide Associations Studies (GWAS) put forward more than 100 loci associated with schizophrenia [6]. Several of the genes associated were related to dopamine receptors D2 (DRD2) and several glutamate associated receptors (GRIA1, GRIN2A, GRM3) [7]. Consistent with genetic studies, drugs known to increase dopamine transmission (amphetamine, L-Dopa) induced schizophrenia like symptoms in controls and exacerbate psychotic symptoms in patients [8]. Conversely, all antipsychotic drugs used in schizophrenia act via blocking of dopamine D2 receptors [9]. Regarding

(c) This is an Open-Access article distributed under the terms of the Creative Commons Attribution Non-Commercial License (http://creativecommons.org/licenses/by-nc/4.0) which permits unrestricted non-commercial use, distribution, and reproduction in any medium, provided the original work is properly cited. 
glutamate involvement, the hypothesis arose from the psychotic effect of drug acting via N-Methyl-D-Aspartate (NMDA) antagonism [10]. More recently, functional brain imaging studies underpinned that schizophrenic patients have activity of the NMDA receptors [10]. Together, these data saw the emergence of two complementary theories based on dopaminergic and/or glutamatergic dysregulation in schizophrenia.

Thus, the central roles of monoamines in schizophrenia pathophysiology were emphasized and biological measures, including lumbar puncture, were conducted in order to directly explore the monoamines metabolism in patients. However, no clear biomarkers have been identified yet, and diagnosis and treatment are only guided by clinical arguments. These data have also motivated research on a biological marker of treatment response as a key issue in schizophrenia.

The synthesis of the three monoamines (Serotonin [5-HT], Noradrenalin [Na], and Dopamine [Da]) is mainly driven from tryptophan, which is an essential amino acid (i.e., only available from exogenous supply) and tyrosine. Dopamine will act on different post-synaptic dopamine receptors (D1-D5) or on a D2 presynaptic axonal, (which decrease dopamine release and neurotransmission). Dopamine can also be reuptaken through dopamine transporters into the presynaptic neuron. Finally, different enzymes, such as catechol-O-methyl-transferase (COMT), monoamine oxidase $A$ (MAO-A), or monoamine oxidase $\mathrm{B}$ (MAO-B) will metabolize dopamine into a final metabolite, homovanillic acid (HVA). Dopamine can also be metabolized into noradrenaline by the dopamine hydroxylase. Noradrenalin is finally catabolized into 3-Methoxy-4-hydroxyphenylglycol (MHPG or MOPEG) [11].

Serotonin is produced from tryptophan by the tryptophan hydroxylase. It acts on the 5-HT receptors on the pre and postsynaptic neurons, and can also be recaptured in the pre-synaptic neuron. Serotonin is catabolized into 5-hydroxyindolamine acetic acid (5-HIAA) by the aldehyde deshydrogenase and the MAO [11].

The synthesis and degradation of monoamines are closely intricated with the metabolism of folates and pterins. Indeed, Methyltetrahydrofolate (MTHF) and Tetrahydrobiopterin $(\mathrm{BH} 4)$ are cofactors of tryptophan hydroxylase and tyrosine hydroxylase, and contribute to the synthesis of the three monoamines [12]. Interestingly, it has been demonstrated that low folate levels was linked with a higher risk of schizophrenia, while the heterozygous mutation MTHFR $677 \mathrm{C} \rightarrow \mathrm{T}$ is associated with a lower response to antipsychotic treatment [13]. This mutation is leading to a folate deficiency in CSF, which can drastically decrease dopamine synthesis [14]. It has also been suggested that MTHF-related hyperhomocysteinemia could be linked to cognitive deficits [15] in schizophrenia, and therefore associated with poorer outcome. $\mathrm{BH} 4$ is derived from neopterin, an enzyme activated by inflammatory cytokines [16]. $\mathrm{BH} 4$ is also implicated in the synthesis of kynurenin and kynurenic acid (KYNA). KYNA is, like serotonin, derived from tryptophan and has antagonist properties on the NMDA receptors. Those glutamate receptors are supposed to have a key role in the physiopathology of schizophrenia [17] (for an overview of monoamine's metabolism; Fig. 1). In the past years, numerous studies have been published about the role of inflammation in both the onset of schizophrenia and its treatment resistance (for review, see [16]). While the exact mechanism between inflammation and schizophrenia has not been yet fully explained, recent findings showed that blood brain barrier might be dysfunctional in patients [18]. Moreover, inflammatory cytokines have been found elevated in the CSF of patients with schizophrenia. Anti-inflammatory properties of antipsychotic drugs have also been demonstrated [19]. Those data have led researchers to propose the use of immunomodulatory drugs as a putative treatment $[20,21]$. Some authors [21] have suggested that chronic inflammation could influence neurotransmitter synthesis by the inhibition of $\mathrm{BH} 4$ and the activation of indolamine 2,3 dioxygenase (IDO), leading to a defect in monoamine metabolism and KYNA synthesis [22].

Direct assessment of dopamine and serotonin is not easy, albeit theoretically possible [23] and plasma levels of HVA and 5-HIAA are not considered as relevant, being influenced by the peripheral metabolism [24]. Moreover, direct study of a patient's brain tissue is not possible for obvious ethical reasons. In consequence, assessment of monoamine's metabolism can only be made by lumbar punctures, allowing direct quantitative analysis of catabolites of dopamine and serotonin (HVA et 5-HIAA) but also pterins (neopterin and $\mathrm{BH} 4$ ). The assessment of CSF monoamines can be challenging in usual practice. Most psychiatrists are not trained to lumbar puncture. This could explain the relative lack of large clinical studies in the last twenty years in this field. However, CSF mono- 


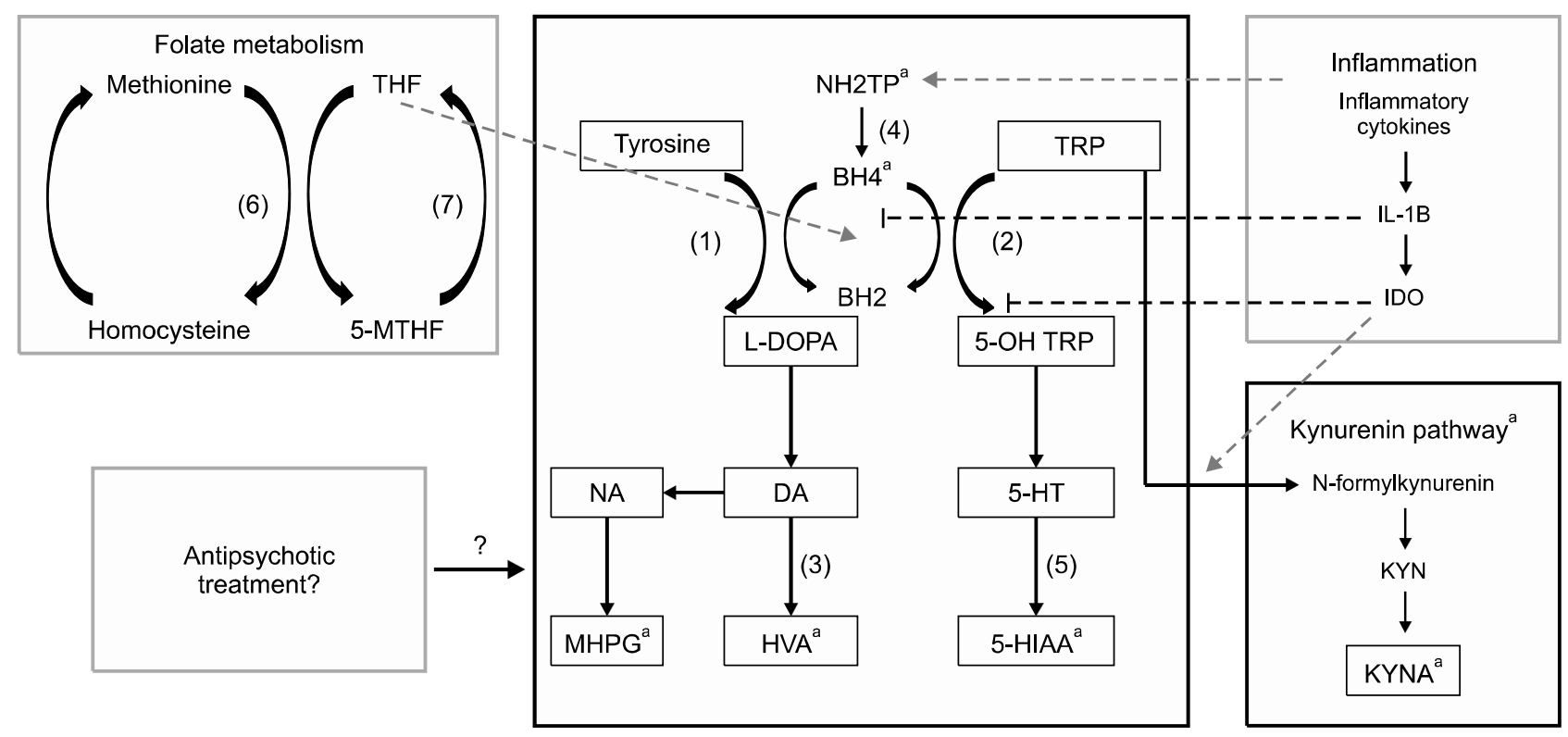

Fig. 1. Overview of monoamine's metabolism. Tyrosin and Tryptophan are metabolized into the three monoamines (dopamine, noradrenalin,and serotonin). Tetrahydrobiopterin and Tetrahydrofolate are cofactors of the synthesis of L-DOPA and 5-OH tryptophan, which are the precursors of Dopamine and serotonin, respectively. Dopamine is catabolized into Homovanillic acid, or metabolized into noradrenalin which is transformed into 3-Methoxy-4-hydroxyphenylglycol. Serotonin is catabolized into 5-hydroxyindolamine acetic acid Inflammatory processes influence monoamine's metabolism by stimulating neopterin. IL-1B inhibits BH4, while IDO inhibits tryptophan hydroxylase and stimulates the kynurenin pathway. (1) Tyrosine Hydroxylase; (2) Tryptophan Hydroxylase; (3) Catecholamine-O-Methyl Transferase (COMT) and Monoamine Oxydase (MAO); (4) 6-Pyruvotetrahydropterin Synthase (PTPS) and Sepiapterin Reductase (SR); (5) Aldehyde Deshydrogenase and MAO; (6) Methionine Synthase; (7) Methyltetrahydrofolate Reductase (MTHFR).

NH2TP, dihydroneopterin triphosphate; BH2, Dihydrobiopterin; BH4, Tetrahydrobiopterin; TRP, Tryptophan; DOPA, Dopamin; NA, Noradrenaline; 5-HT, serotonin; MHPG, 3-Methoxy-4-hydroxyphenylglycol; HVA, Homovanillic acid; 5-HIAA, 5-hydroxyindolamine acetic acid. ${ }^{\mathrm{a}} \mathrm{Can}$ be measured in CSF.

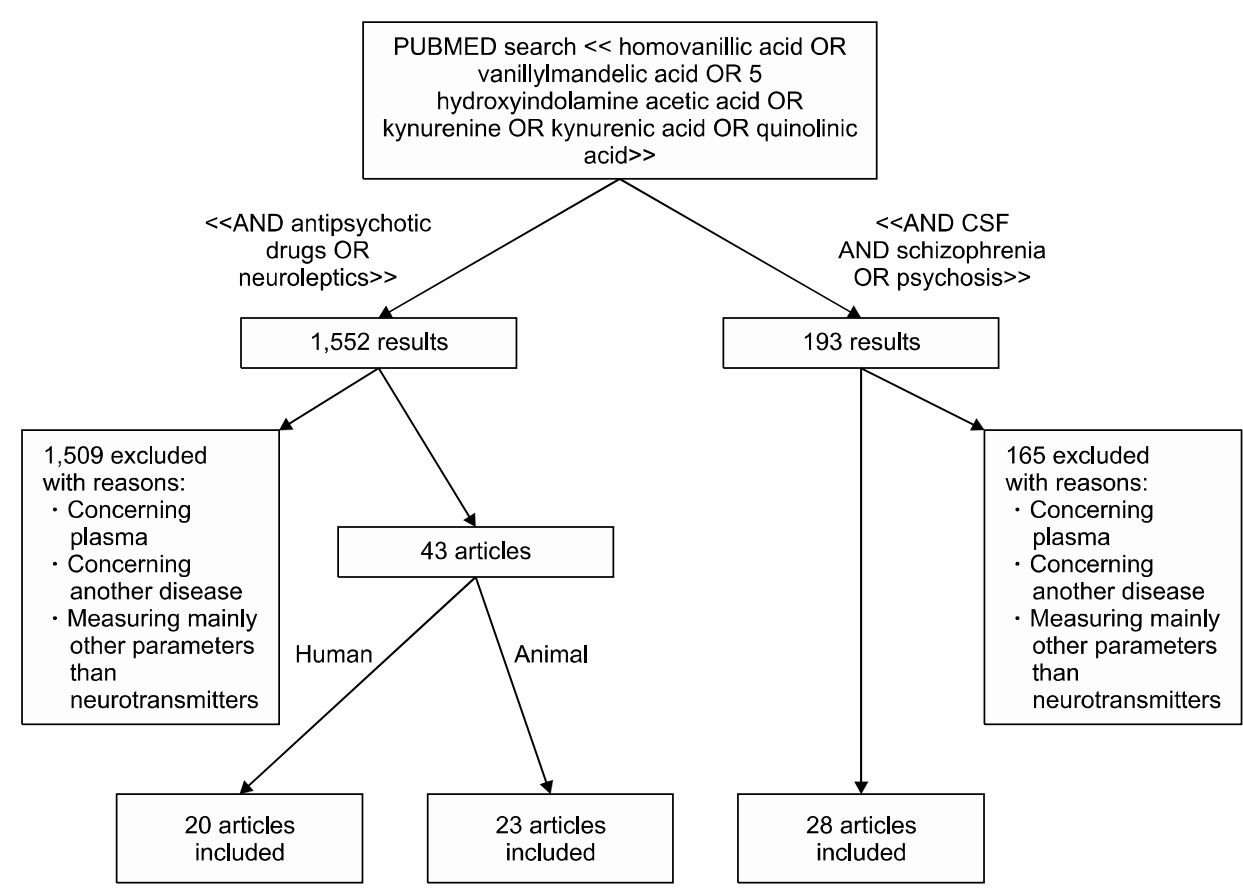

Fig. 2. Flowchart of article selection process. 
amines are a key part in the understanding of schizophrenia's physiopathology, being at the crossroad of several mechanisms implicated in this disease. This comprehensive review aims to synthesize CSF studies on monoamine metabolism in schizophrenia, and the influence of the antipsychotic medication.

\section{METHODS}

Researches have been conducted by two independent clinicians on PubMed on October 2nd, 2018 (Fig. 2). The first research was conducted with the following MeSH terms: [homovanillic acid] OR [vanillylmandelic acid] OR [5-hydroxyindolamine acetic acid] OR [kynurenine] OR [kynurenic acid] OR [quinolinic acid] AND [CSF] AND [schizophrenia] OR [psychosis]. The articles pertinence was assessed based on the abstracts and/or the fulltexts. We selected 28 articles and the key messages were summarized.

The second research, conducted with the terms [homovanillic acid] OR [vanillylmandelic acid] OR [5-hydroxyindolamine acetic acid] OR [kynurenine] OR [kynurenic acid] OR [quinolinic acid] AND [antipsychotic] OR [neuroleptic]. The articles pertinence was assessed based on the abstracts and/or the full-texts. We selected 43 articles and the key messages were summarized.

The following MeSH terms (serotonin OR norepinephrine OR dopamine) were not used, in order to narrow the research results to articles that explore specifically central monoamine metabolism.

\section{RESULTS}

\section{Clinical Studies of CSF Neurotransmitters}

Six clinical studies CSF HVA and CSF5-HIAA in patients with schizophrenia and control subjects (Table 1).

Two studies find no difference in HVA, 5-HIAA and MHPG between patients with schizophrenia and healthy controls [25,26]. Bjerkensted et al. [27] finds reduction of HVA in patients, compared to controls, but no difference in 5-HIAA. To note, $50 \%$ of the patients are admitted for a first episode, and are therefore naïve of treatment. Another study from this cohort [28] shows a lower CSF HVA in the first episode and drug naïve patients with schizophrenia, compared to controls. Two other studies with drug free patients find low CSF HVA compared to healthy volun- teers $[29,30]$. In those studies, 5-HIAA is not different between patients and controls.

Considering the co-factors, a study [31] finds no difference between CSF neopterin in patients with schizophrenia compared to healthy controls. At our knowledge, there is no study comparing CSF biopterin between healthy controls and schizophrenia.

In sum, the heterogeneity of results concerning CSF HVA and 5-HIAA might be explained by the heterogeneity of patients. Indeed, several clinical parameters could influence the levels of monoamines (e.g., presence of a pre-existing treatment, disease duration and severity).

\section{Correlations with Morphological Imagery Studies}

The diminution of cerebral volume and the enlargement of the cerebral ventricles in schizophrenia is one of the most replicated findings [1]. Studies correlating CSF monoamines levels and cerebral ventricle size in patients with schizophrenia find a negative correlation with HVA and HVA/5-HIAA ratio $[26,32]$. Houston and colleagues [33] also find that the size of the third ventricle is negatively correlated with CSF HVA levels in schizophrenia. They suggest that this correlation may result from a progressive and time-dependent atrophy of dopaminergic neurons. However, a study measuring CSF HVA levels in adolescent patients with schizophrenia find a negative correlation between ventricle-brain ratio and CSF HVA [34]. It seems to indicate that a negative correlation between ventricle size and CSF HVA is present at an early stage of the disease.

In sum, CSF HVA level seems to be inversely correlated with ventricle size, at any stage of schizophrenia. This negative correlation is also found with 5-HIAA [26], in particular in adolescents with schizophrenia [34]. Mechanisms underpinning those resulte are not clear. All these studies are made with computed tomography-scan, and to our knowledge, no recent work linked cerebral imagery and CSF monoamines, using more precise imaging techniques (e.g., structural magnetic resonance imaging or functional imagery).

\section{Correlations with Disease Severity and Treatment Outcome}

Homogenizing on disease severity or treatment response might reduce the heterogeneity of monoamines results in CSF. Early reports show that low CSF 5-HIAA is 


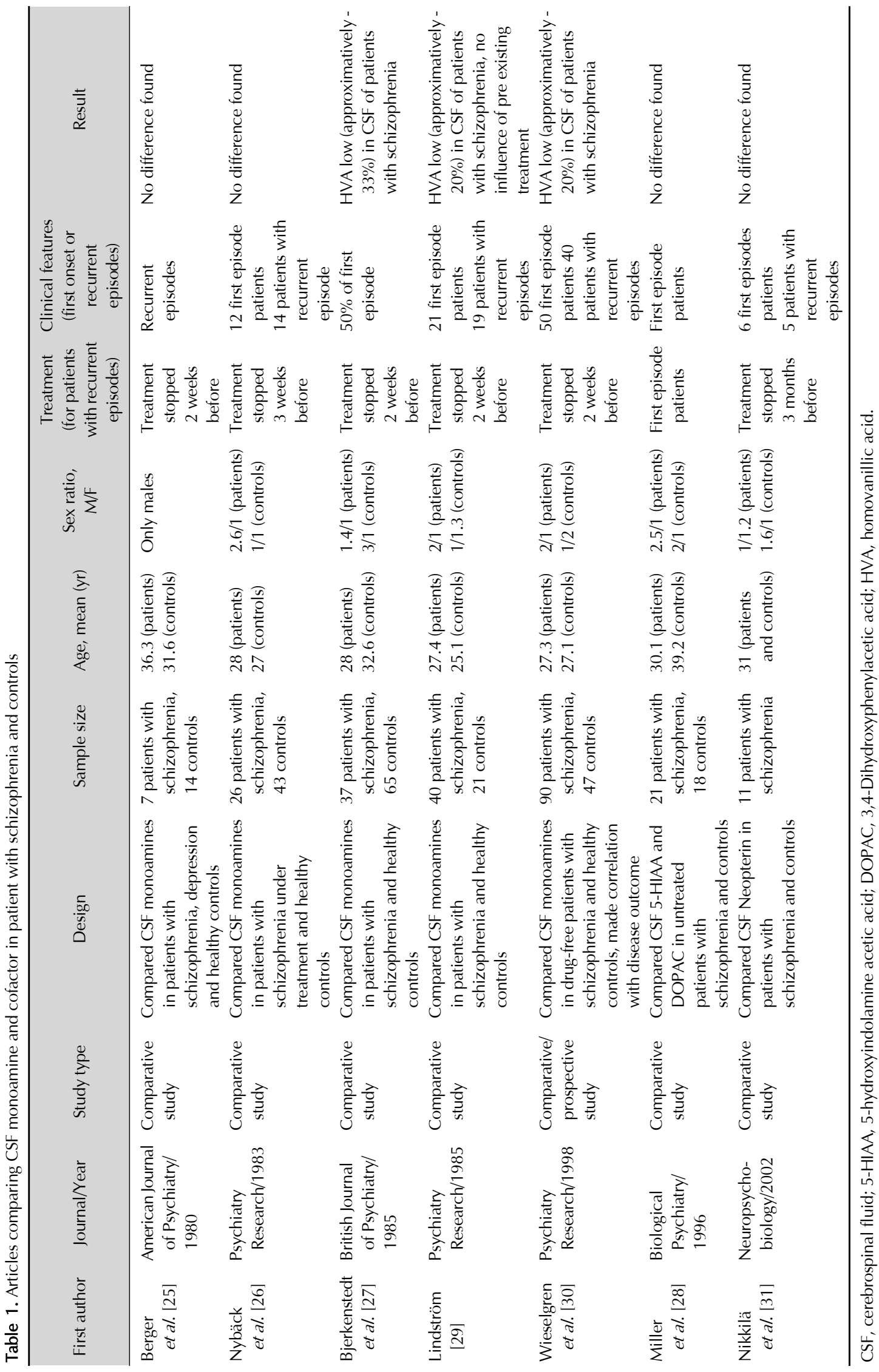


correlated with both negative symptoms and delusions $[35,36]$. On the other hand, low CSF HVA is also correlated with positive symptoms [35]. A 28-year longitudinal study [37] shows that low CSF HVA/5-HIAA ratio was associated with a greater risk of suicide, but do not consider symptom's severity as a confounding factor to interpret that result. In another report on a five-year longitudinal study [30], a low CSF HVA/5-HIAA quotient at baseline is correlated to a poorer outcome. Three different studies find on the contrary that a low HVA/5-HIAA ratio in CSF predicted a good response to clozapine [38-40] (for a review see also [41]).

The response to antipsychotic seems also linked with kinetic changes in CSF monoamines. HVA/5-HIAA ratio increases more in patients showing short-term improvement after haloperidol prescription [42]. Another study [43] finds that HVA rising from baseline to 4 weeks after the beginning of treatment is a predictor of poor outcome. This result is partially replicated [44], CSF HVA and 5-HIAA augmentation being inversely correlated with both positive and negative symptoms.

In sum, monoamine's levels, especially the HVA/5-HIAA ratio, seems to be negatively correlated to treatment's outcome, except for clozapine. Furthermore, an early kinetic change in that ratio appears to be a good predictor of treatment response.

\section{Correlation with the Kynurenine Pathway}

Kynurenic acid (KYNA) and quinolinic are catabolites of tryptophan, and can be easily measured in the CSF. Given the NMDA-R antagonist effects of KYNA, a role of KYNA in the onset of psychotic symptoms is suggested in recent studies [17]. This hypothesis seems to be confirmed by the fact that elevated KYNA levels are found on brain patients autopsies [45].

Elevated levels of KYNA in the CSF is correlated with a patient's age [46]. This result is confirmed by a study on a larger sample of patients [47], in which no influence of the antipsychotic treatment and the elevation of KYNA is found. Moreover, tryptophan level in CSF do not seem different in schizophrenia, even in a sample of patients with elevated CSF KYNA levels [48]. Those results are sampled in a meta-analysis [22], that confirms the previous findings.

In sum, KYNA levels appear to be increased in schizophrenia, independently of the tryptophan levels.

\section{Effect of Antipsychotic Treatment on CSF Monoamines}

Considering the importance of monoamine metabolism in the pathophysiology of schizophrenia, many studies were led to assess the effect of antipsychotic treatment on CSF NT.

\section{Animal studies}

We summarize the studies on animals (all the studies presented below were done on rats) on the effect of antipsychotics. We separate them in two groups (i) immediate (i.e., in the first days of administration) effect of neuroleptics on HVA, (ii) effect of chronic administration (i.e., after one month of administration).

\section{Initial phase of antipsychotic administration: increase of HVA}

After administration of antipsychotic, HVA production increase. This increase seems to be dose and product-dependant: Haloperidol $\geq$ fluphenazine $>$ loxapine $>$ trifluoperazine $>$ thiothixene $>$ molindone $>$ clopenthixol $>$ chlorpromazine $>$ thioridazine $>$ clozapine $>$ sulpiride [49-54]. The intensity and duration of HVA increase might also be region-dependent. Indeed, it is more important in the striatum compared to olfactory tubercle and limbic regions and more important in the caudate compared to the prefrontal cortex [50,52,55-58].

In synthesis, considering the drug and the regional brain area, early after administration in animals:

- Risperidone increases 3,4-Dihydroxyphenylacetic acid (DOPAC, an intermediate catabolite of DA) and DOPAC/DA ratio in the striatum, but less than haloperidol. Moreover, it increases the 5-HIAA/5-HT ratio in the hippocampus [59].

- Aripiprazole does not modify dopamine levels but increases moderately DOPAC and HVA and reduces 5-HIAA in the striatum and the medial prefrontal cortex [60].

- Olanzapine increases more notably DA, HVA, and DOPAC in striatum and medial prefrontal cortex, without modifying 5-HT and 5-HIAA [61].

- Clozapine increases DA, DOPAC, and HVA concentrations in mesocortical prefrontal cortex, but causes no changes in the nucleus accumbens and striatum, hence its specific action on the mesocortical DA pathway [62]. Another study showes different results, as acute administration of clozapine increases HVA, 
HVA/DA ratio, and DOPAC in the striatum, and decreases DOPAC in other brain regions [63].

\section{Chronic phase after continued antipsychotic administration: HVA decreases}

After an initial augmentation, chronic (i.e., superior to 1 month) administration of antipsychotic in rats is associated with HVA decrease $[61,64,65]$. It is suggested that the augmentation could be driven by an initial enhancement of DA metabolism due to D2-blocking, especially in the prefrontal cortex [66] associated with the enhancement of DA firing. This hypothesis is supported by the augmentation of DA in the substantia nigra, even after chronic administration [65]. The HVA decreases with a tolerance mechanism set up in the prefrontal cortex, underpinned by a D2 receptor proliferation and a decrease of initial DA firing [54]. This diminution of DA firing does not appear after 21 day of clozapine administration [66-68]. Exploring more specifically those kinetic changes, HVA decreases more in the caudate nucleus versus the limbic region $[67,69]$. In monkeys, it has been suggested that this decrease could be associated with tardive dyskinesia $[67,68]$.

Besides, decrease of HVA seems specific to the antipsychotic used: within a week for chlorpromazine, within two weeks for clozapine [69]. A study comparing HVA levels in rats after 3 weeks of olanzapine or aripiprazole shows increased HVA in CSF $[60,61]$. On the other hand, eight-month treatment with long-acting fluphenazine is associated with HVA increase in the striatum [70].

In sum, chronic administration of antipsychotics results in a dose-dependent increase of HVA in the striatum in the first month followed by a progressive decrease. This normalization could be explained by tolerance mechanisms. The heterogeneity of results by antipsychotics suggests that this mechanism could be influenced by specific receptor profiles. The results are presented in Table 2.

\section{Human studies}

After four weeks of antipsychotic, an HVA augmentation is observed [42,71-74]. Only two studies [43,75] show no significant difference. Another group of studies describe the evolution of CSF HVA on a larger time window (8 weeks). After an augmentation in the first 4 weeks, they show a diminution of HVA levels $[76,77]$. No difference is found on CSF 5-HIAA levels. Quetiapine and
Olanzapine are responsible for an elevation of CSF HVA after 4 and 6 weeks respectively, without difference on 5-HIAA $[44,78]$. Interestingly, studies on clozapine do not find difference in HVA levels after 4 weeks of treatment $[39,79]$.

A third group of studies assess the effect of antipsychotic withdrawal on CSF monoamines. They find a global decrease of both HVA and 5-HIAA [80-82] correlated with increased symptoms [83]. This effect is more important in the CSF of less severe patients [84].

Few studies investigated the effect of antipsychotic on CSF 5-HIAA levels: while haloperidol [72] and quetiapine [44] enhance 5-HIAA levels in CSF after 2 and 4 weeks of treatment, those levels remain unchanged after 4 weeks of sulpiride and chlorpromazine [76,77]. No difference were observed after 5 weeks of haloperidol [42], 6 weeks of olanzapine [78], and clozapine decreases CSF 5-HIAA levels after 3 weeks of treatment.

In sum, based on animals and humans' studies CSF HVA seems to be increased in the first weeks of treatment. After one month, CSF HVA normalizes, perhaps longer with second generation antipsychotics. It is unclear how antipsychotic prescription modifies CSF 5-HIAA. Human studies show that antipsychotic withdrawal induced a fall of both CSF HVA and 5-HIAA, correlating with symptoms worsening.

The results are presented in Table 3.

\section{DISCUSSION}

\section{Is CSF Monoamines Level Different in Schizophrenia? Can It Be Used as a Biomarker of Severity?}

Studies on CSF monoamines in schizophrenia are published for more than fifty years. It appears that no evident difference can be drawn between schizophrenia and controls. Several limitations should be considered: (i) In most of these studies, neuroleptic medication is stopped several weeks before the lumbar puncture, which, as we have seen, lead to an underestimation of CSF HVA. (ii) The lack of data on other CSF or plasmatic measurement that could influence CSF monoamines level. In particular, none of this study investigates MTHF levels in plasma or CSF. Indeed, MTHF has a major role in monoamine's metabolism and could thus influence their CSF levels [85]. Furthermore, inflammatory processes could also influence monoamine synthesis [21], and none of the study as- 


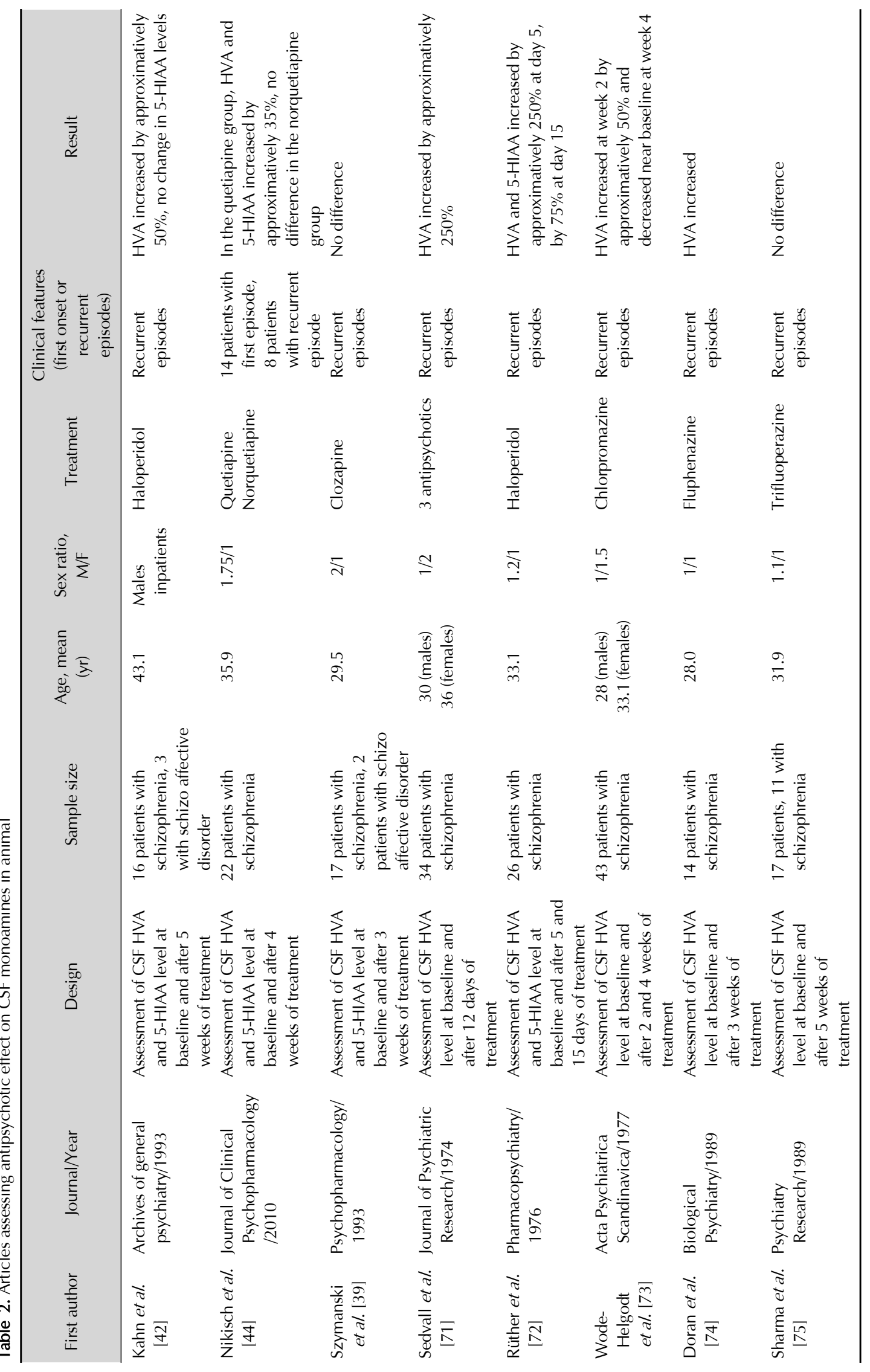




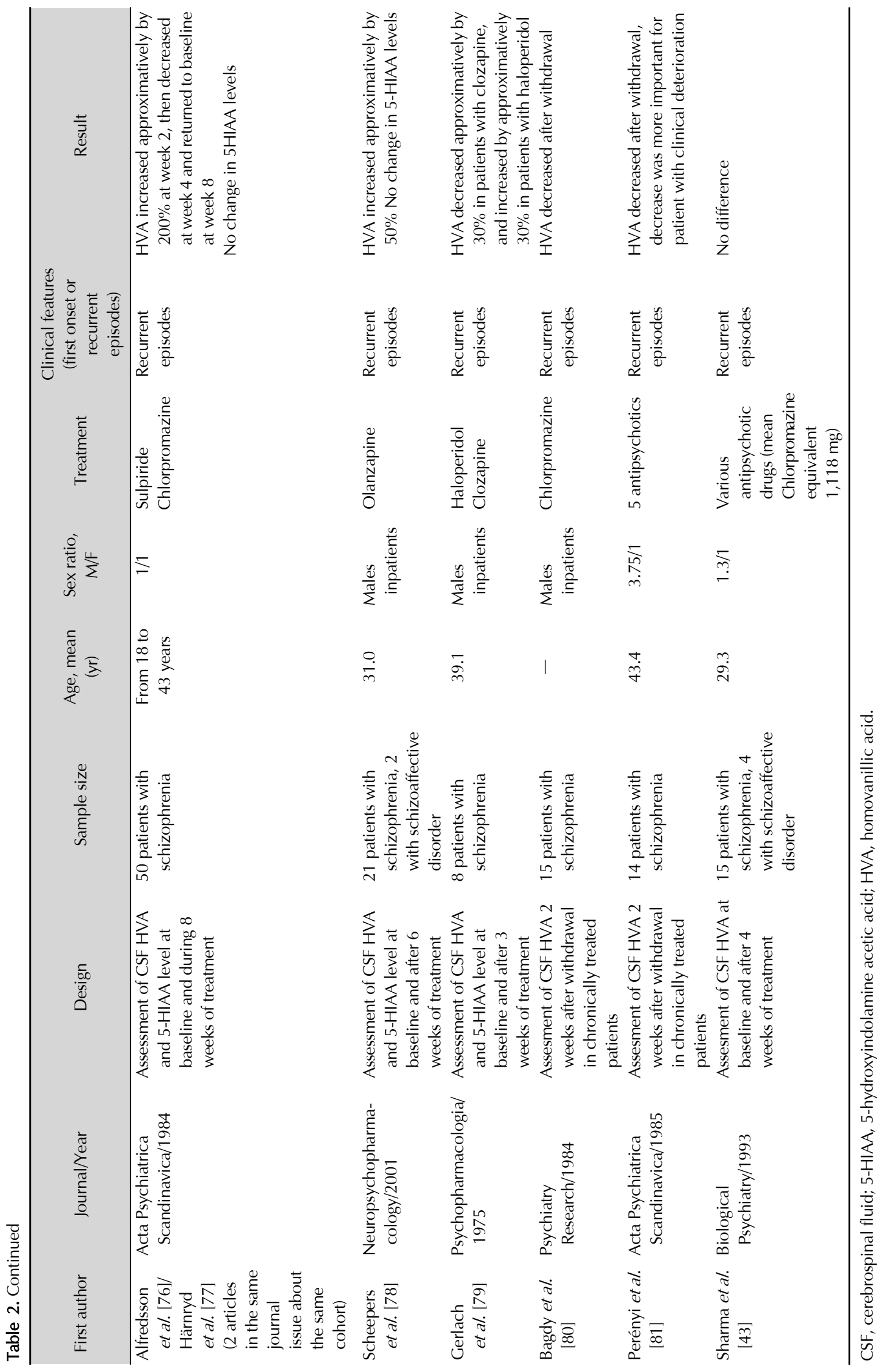




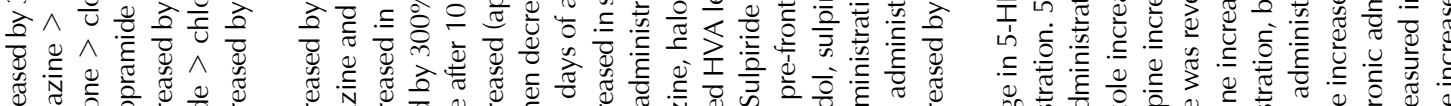

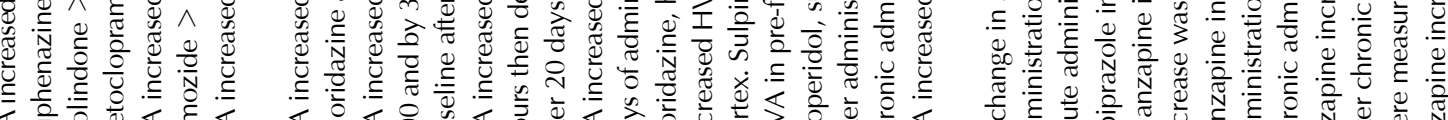

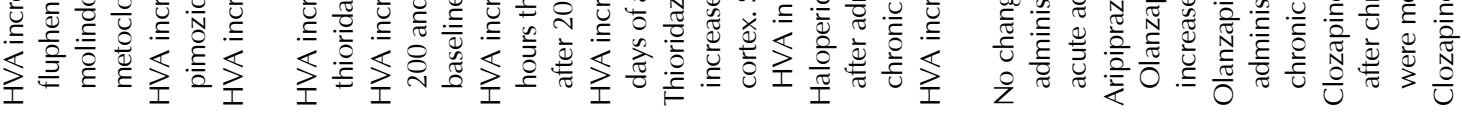

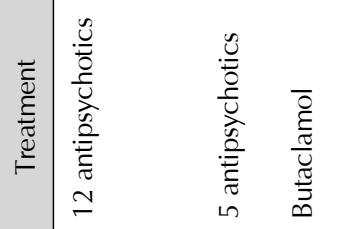

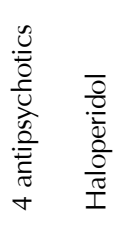

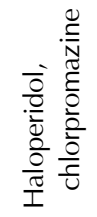

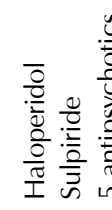

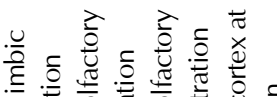

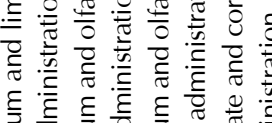

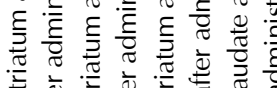

ᄃ

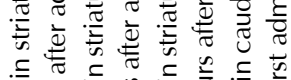

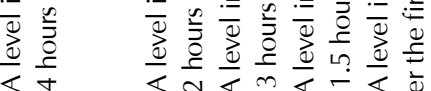

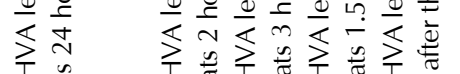

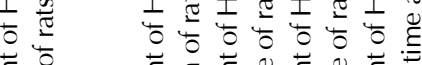

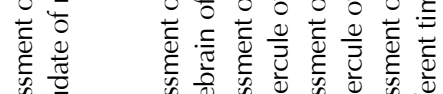

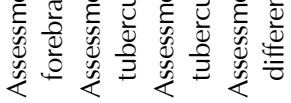

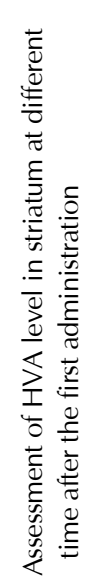

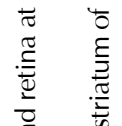

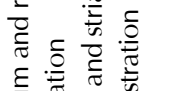

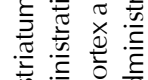

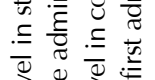

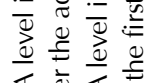

交离市离

है

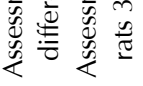

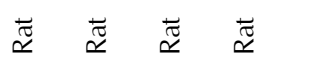

व्ञ

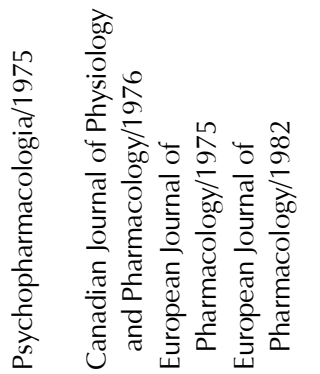

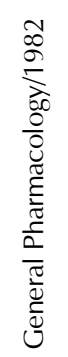

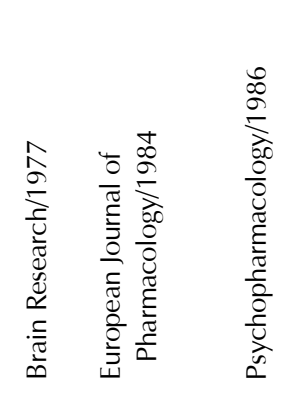

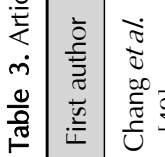

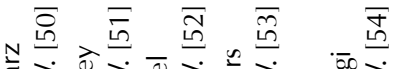

\section{$\sqrt{\frac{5}{8}}$}

量要

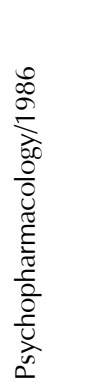

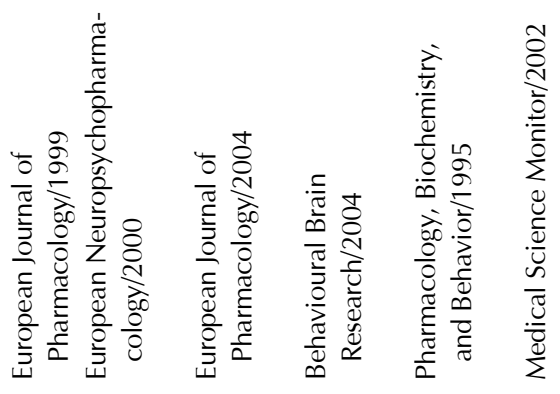

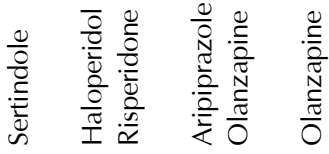

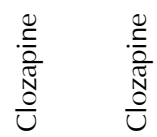

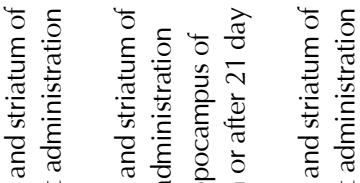

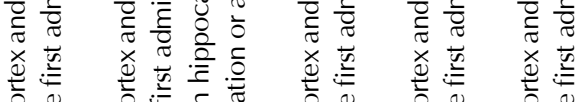

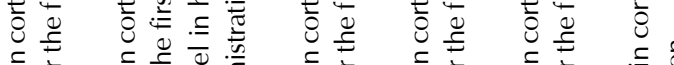

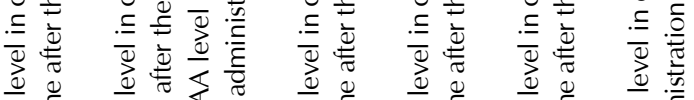

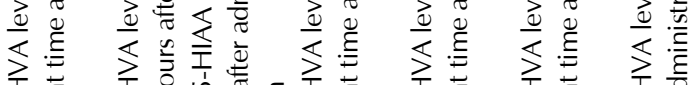

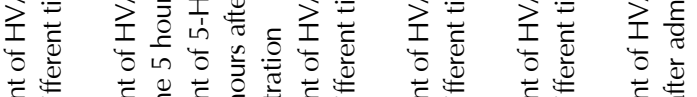

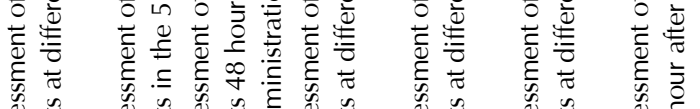

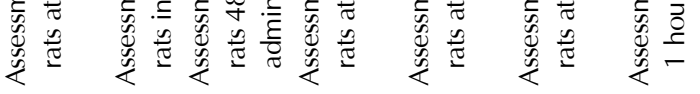

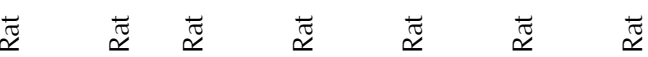

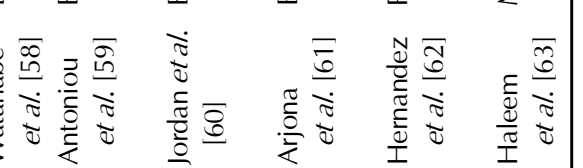




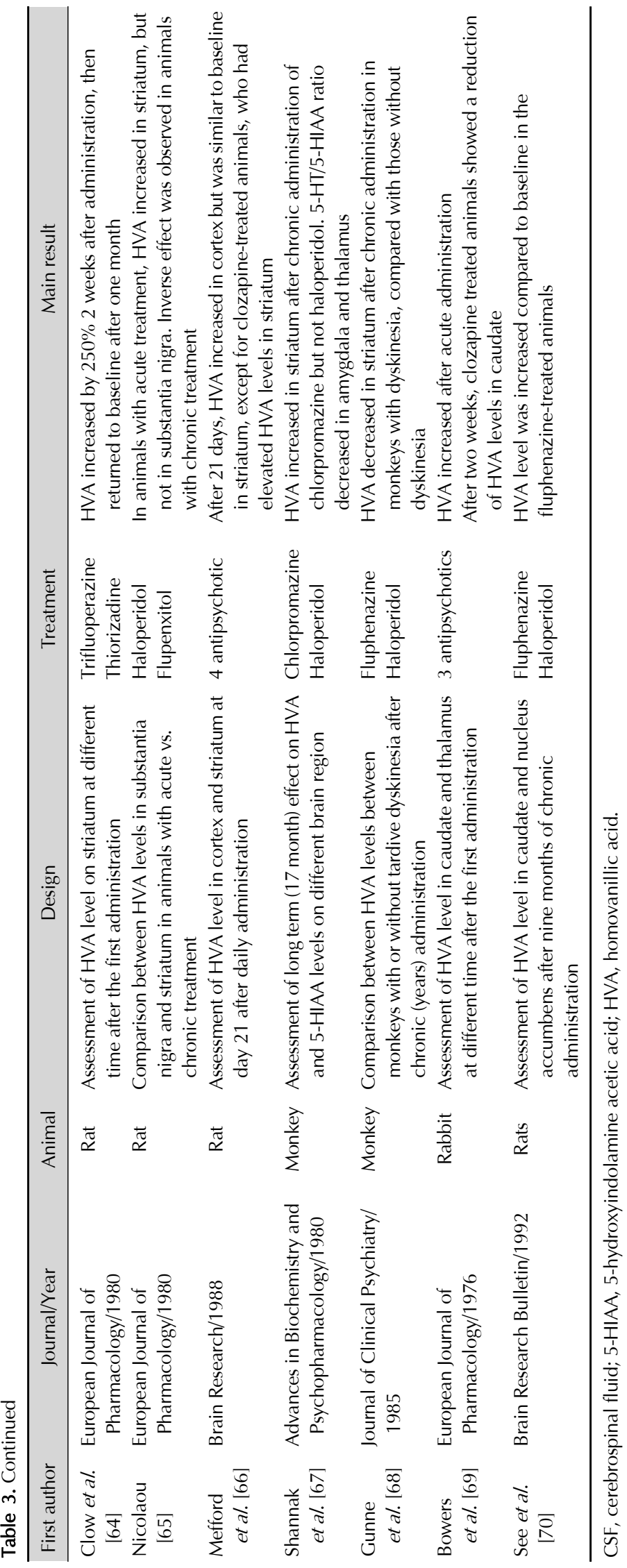


sessed inflammatory markers with monoamine metabolism.

Our review also suggests that low CSF HVA, could be correlated with clinical features, such as positive symptoms. Those results can lead to the hypothesis that perturbed CSF monoamines levels (i.e., low CSF HVA and low HVA/5-HIAA) could be both a marker of severity and a negative predictor of treatment response. This hypothesis can be supported by the fact that CSF HVA seems to be inversely correlated to the cerebral ventricle size, which has been found enlarged in patients with poor outcome [86]. Future studies are needed in order to assess the differences in monoamines CSF between responder and nonresponders to antipsychotic treatment.

\section{How Can the Antipsychotic Action on CSF be Modeled?}

There is a good concordance between animal and human studies about CSF HVA and antipsychotic effects (Fig. 3). Indeed, an augmentation of HVA levels in CSF in the first week (with both first and second-generation antipsychotics), normalization after 8 weeks, and a brutal de- crease in case of treatment withdrawal. A first hypothesis is that D2-blocking increases the catabolism of dopamine, leading to HVA augmentation in CSF [34]. After a few weeks ( $2-4$ weeks) the normalization could be explained [77] by an up-regulation in the striatal D2 receptors. A second explanation proposes [82] that D2-blocking increased the dopamine release in the striatum (responsible for the majority of HVA production) [87] followed by normalization after a few weeks. This augmentation of CSF HVA seems to be correlated to treatment response [44]. We make a third hypothesis of this biphasic evolution, and suppose that antipsychotic drugs could also have an influence on biopterin and neopterin. However, because 5-HIAA level does not seem to be affected by neuroleptics, and since no data is available on an antipsychotic effect on CSF biopterin or neopterin have been found, this hypothesis can not be verified.

To note, the specific profile of CSF HVA response to clozapine could be explained [39] by the specific serotonindopamine interactions profile of this drug (i.e., 5-HT2A blockade leading to pro-dopaminergic action). This ac-

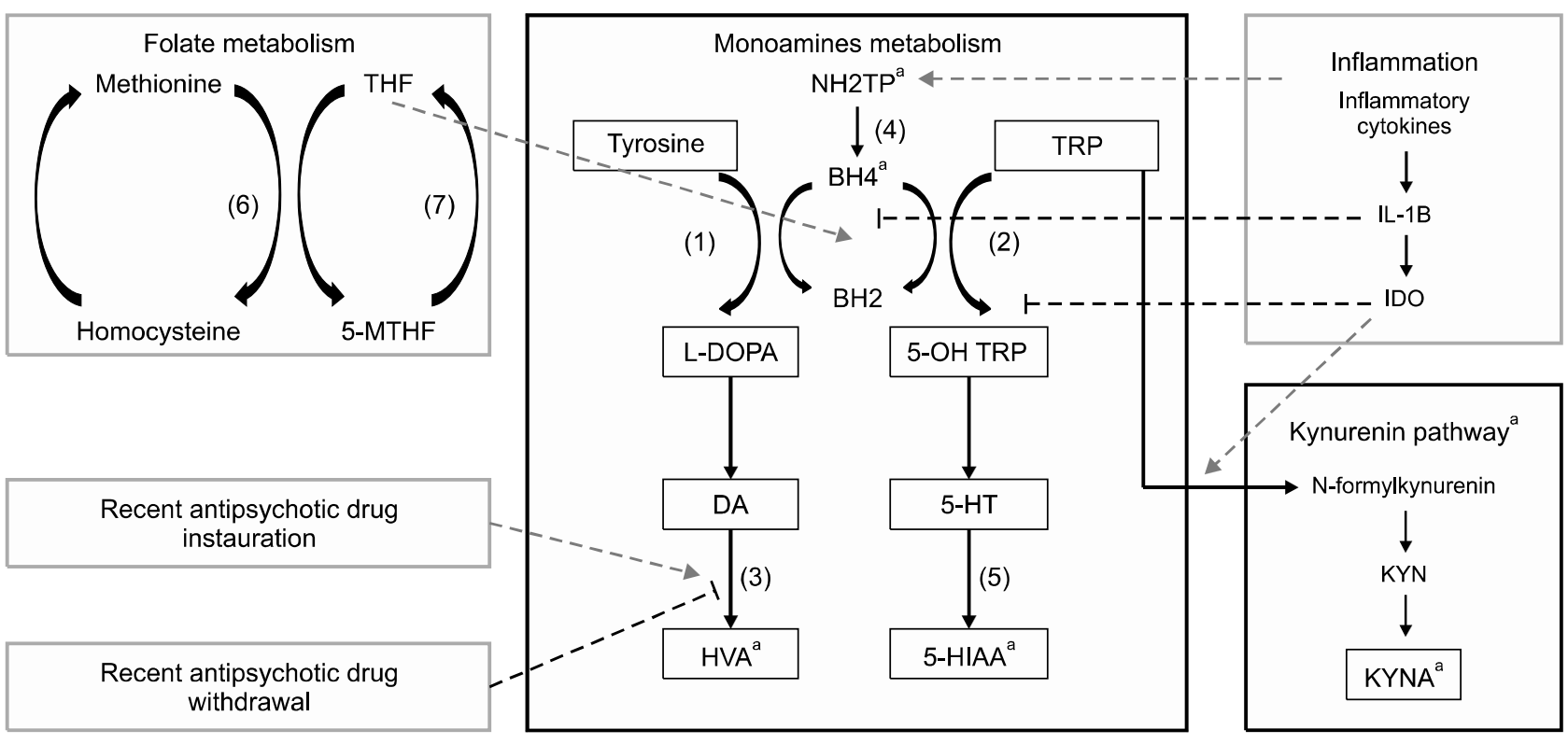

Fig. 3. Overview of monoamine's metabolism and the antipsychotic effect on CSF HVA. Antipsychotics influence monoamine's metabolism by stimulating HVA production after its instauration. Withdrawal provokes a decrease in HVA level. Antipsychotic prescription should be considered as a confounding factor as well as inflammatory processes and folate metabolism when monoamine's assessment is performed. (1) Tyrosine Hydroxylase; (2) Tryptophan Hydroxylase; (3) Catecholamine-O-Methyl Transferase (COMT) and Monoamine Oxydase (MAO); (4) 6-Pyruvotetrahydropterin Synthase (PTPS) and Sepiapterin Reductase (SR); (5) Aldehyde Deshydrogenase and MAO; (6) Methionine Synthase; (7) Methyltetrahydrofolate Reductase (MTHFR).

NH2TP, dihydroneopterin triphosphate; BH2, Dihydrobiopterin; BH4, Tetrahydrobiopterin; TRP, Tryptophan; DOPA, Dopamin; NA, Noradrenaline; 5-HT, serotonin; MHPG, 3-Methoxy-4-hydroxyphenylglycol; HVA, Homovanillic acid; 5-HIAA, 5-hydroxyindolamine acetic acid.

${ }^{\mathrm{a}} \mathrm{Can}$ be measured in CSF. 
tion on the $5 \mathrm{HT}$ receptor is not specific of clozapine, being one the main mechanisms of second-generation antipsychotics.

Our review does not support the hypothesis of an isolated dysfunction of monoamines metabolism in schizophrenia, as it has been formulated by the first studies on this field $[35,71]$. However, the antipsychotic treatments disturb CSF monoamines in a time-dependent matter. Influence of antipsychotic drugs could have been a major bias for the interpretation of CSF monoamines. All those considerations encourage assessing monoamines in CSF more frequently in patients with schizophrenia, and to consider the confounding factors we cited: (i) measurement of inflammatory processes (ii) assessment of folate metabolism, specifically the presence of $\mathrm{c} 677 \mathrm{t}$ MTHFR mutation (iii) control of antipsychotic treatment.

Moreover, the importance of the lumbar punctures' quality, and specifically its standardization (i.e., CSF sample used to investigate neurotransmitters metabolism should always be taken at the same moment of the puncture), the concentration of monoamine metabolites is also influenced by a cranio-caudal gradient [88].

Our literature review is comprehensive; thus, it might be useful to perform a meta-analysis of the relationship between CSF monoamines levels and treatment response or schizophrenia subtype, in order to consider the heterogeneity of the study we reviewed.

Further studies on this field could help finding the missing link between inflammatory processes, folate metabolism and antipsychotic effect on the disease course (Fig. 3).

\section{CONCLUSION}

As research of a biomarker plays a crucial role in the treatment of schizophrenia, studies on monoamines metabolites in CSF reveals that those levels could be correlated to disease severity and to specific clinical features. While the antipsychotic treatment seems to provoke changes in CSF HVA, further studies should consider the antipsychotic treatment as a potential confounding factor, and consider the central place of neurotransmitters metabolism in metabolic and inflammatory processes involved in schizophrenia.

\section{- Conflicts of Interest}

No potential conflict of interest relevant to this article was reported.

\section{Author Contributions}

Conceptualization: Matthieu Gasnier, Marion Plaze, Pierre Abdel Ahad. Litterature screening: Matthieu Gasnier, Pierre Abdel Ahad. Writing and reviewing: Matthieu Gasnier, Pierre Ellul.

\section{ORCID}

Matthieu Gasnier https://orcid.org/0000-0003-4887-4025 Pierre Ellul https://orcid.org/0000-0003-1862-6952 Marion Plaze https://orcid.org/0000-0001-9022-4945 Pierre Abdel Ahad https://orcid.org/0000-0002-2731-6721

\section{REFERENCES}

1. Owen MJ, Sawa A, Mortensen PB. Schizophrenia. Lancet 2016;388:86-97.

2. Howes OD, McCutcheon R, Agid O, de Bartolomeis A, van Beveren NJ, Birnbaum ML, et al. Treatment-resistant schizophrenia: Treatment Response and Resistance in Psychosis (TRRIP) working group consensus guidelines on diagnosis and terminology. Am J Psychiatry 2017;174:216-229.

3. Delay J, Deniker P. Neuroleptic effects of chlorpromazine in therapeutics of neuropsychiatry. Int Rec Med Gen Pract Clin 1955; 168:318-326.

4. Millan MJ, Andrieux A, Bartzokis G, Cadenhead K, Dazzan P, Fusar-Poli P, et al. Altering the course of schizophrenia: progress and perspectives. Nat Rev Drug Discov 2016;15:485-515.

5. Birnbaum R, Weinberger DR. Genetic insights into the neurodevelopmental origins of schizophrenia. Nat Rev Neurosci 2017;18:727-740.

6. Schizophrenia Working Group of the Psychiatric Genomics Consortium. Biological insights from 108 schizophrenia-associated genetic loci. Nature 2014;511:421-427.

7. Smeland OB, Frei O, Dale AM, Andreassen OA. The polygenic architecture of schizophrenia - rethinking pathogenesis and nosology. Nat Rev Neurol 2020;16:366-379.

8. Grace AA. Dysregulation of the dopamine system in the pathophysiology of schizophrenia and depression. Nat Rev NeurosCi 2016;17:524-532.

9. Jauhar S, Veronese M, Nour MM, Rogdaki M, Hathway P, Natesan S, et al. The effects of antipsychotic treatment on presynaptic dopamine synthesis capacity in first-episode psychosis: a positron emission tomography study. Biol Psychiatry 2019;85:79-87.

10. Hardingham GE, Do KQ. Linking early-life NMDAR hypofunction and oxidative stress in schizophrenia pathogenesis. Nat Rev Neurosci 2016;17:125-134.

11. Stahl SM, Stahl's essential psychopharmacology: neuroscientific basis and practical applications. Cambridge:Cambridge University Press;2013. $625 p$. 
12. Ramaekers VT, Thöny B, Sequeira JM, Ansseau M, Philippe $P$, Boemer $\mathrm{F}$, et al. Folinic acid treatment for schizophrenia associated with folate receptor autoantibodies. Mol Genet Metab 2014;113:307-314.

13. Fryar-Williams S. Fundamental role of methylenetetrahydrofolate reductase $677 C \rightarrow$ T genotype and flavin compounds in biochemical phenotypes for schizophrenia and schizoaffective psychosis. Front Psychiatry 2016;7:172.

14. Wan L, Li Y, Zhang Z, Sun Z, He Y, Li R. Methylenetetrahydrofolate reductase and psychiatric diseases. Trans/ Psychiatry 2018;8:242.

15. Moustafa AA, Hewedi DH, Eissa AM, Frydecka D, Misiak B. Homocysteine levels in schizophrenia and affective disorders-focus on cognition. Front Behav Neurosci 2014;8:343.

16. Müller N. Inflammation in schizophrenia: pathogenetic aspects and therapeutic considerations. Schizophr Bull 2018;44:973982.

17. Vinckier F, Gaillard R, Palminteri S, Rigoux L, Salvador A, Fornito A, et al. Confidence and psychosis: a neuro-computational account of contingency learning disruption by NMDA blockade. Mol Psychiatry 2016;21:946-955.

18. Orlovska-Waast S, Köhler-Forsberg O, Brix SW, Nordentoft M, Kondziella D, Krogh J, et al. Cerebrospinal fluid markers of inflammation and infections in schizophrenia and affective disorders: a systematic review and meta-analysis. Mol Psychiatry 2019;24:869-887.

19. Juncal-Ruiz M, Riesco-Dávila L, Ortiz-García de la Foz V, Martínez-Garcia O, Ramírez-Bonilla M, Ocejo-Viñals JG, et al. Comparison of the anti-inflammatory effect of aripiprazole and risperidone in 75 drug-naive first episode psychosis individuals: a 3 months randomized study. Schizophr Res 2018;202:226-233.

20. Borovcanin MM, Jovanovic I, Radosavljevic G, Pantic J, Minic Janicijevic S, Arsenijevic N, et al. Interleukin-6 in schizophrenia- is there a therapeutic relevance? Front Psychiatry 2017;8:221.

21. Ellul P, Mariotti-Ferrandiz E, Leboyer M, Klatzmann D. Regulatory T cells As supporters of psychoimmune resilience: toward immunotherapy of major depressive disorder. Front Neurol 2018;9:167.

22. Plitman E, Iwata Y, Caravaggio F, Nakajima S, Chung JK, Gerretsen $\mathrm{P}$, et al. Kynurenic acid in schizophrenia: a systematic review and meta-analysis. Schizophr Bull 2017;43:764777.

23. Scheinin M, Seppala T, Koulu M, Linnoila M. Determination of conjugated dopamine in cerebrospinal fluid from humans and non-human primates with high performance liquid chromatography using electrochemical detection. Acta Pharmacol Toxicol (Copenh) 1984;55:88-94.

24. Davis KL, Kahn RS, Ko G, Davidson M. Dopamine in schizophrenia: a review and reconceptualization. Am J Psychiatry 1991;148:1474-1486.

25. Berger PA, Faull KF, Kilkowski J, Anderson PJ, Kraemer H,
Davis KL, et al. CSF monoamine metabolites in depression and schizophrenia. Am J Psychiatry 1980;137:174-180.

26. Nybäck H, Berggren BM, Hindmarsh T, Sedvall G, Wiesel FA. Cerebroventricular size and cerebrospinal fluid monoamine metabolites in schizophrenic patients and healthy volunteers. Psychiatry Res 1983;9:301-308.

27. Bjerkenstedt L, Edman G, Hagenfeldt L, Sedvall G, Wiesel FA. Plasma amino acids in relation to cerebrospinal fluid monoamine metabolites in schizophrenic patients and healthy controls. Br J Psychiatry 1985; 147:276-282.

28. Miller C, Kirchmair R, Troger J, Saria A, Fleischhacker WW, Fischer-Colbrie R, et al. CSF of neuroleptic-naive first-episode schizophrenic patients: levels of biogenic amines, substance $P$, and peptides derived from chromogranin A (GE-25) and secretogranin II (secretoneurin). Biol Psychiatry 1996;39:911-918.

29. Lindström LH. Low HVA and normal 5HIAA CSF levels in drug-free schizophrenic patients compared to healthy volunteers: correlations to symptomatology and family history. Psychiatry Res 1985;14:265-273.

30. Wieselgren IM, Lindström LH. CSF levels of HVA and 5-HIAA in drug-free schizophrenic patients and healthy controls: a prospective study focused on their predictive value for outcome in schizophrenia. Psychiatry Res 1998;81:101-110.

31. Nikkilä HV, Ahokas A, Wahlbeck K, Rimón R, Andersson LC. Neopterin and macrophage inflammatory protein-1alpha in the cerebrospinal fluid of schizophrenic patients: no evidence of intrathecal inflammation. Neuropsychobiology 2002;46: 169-172.

32. Lewine RR, Risch SC, Risby E, Stipetic M, Jewart RD, Eccard $\mathrm{M}$, et al. Lateral ventricle-brain ratio and balance between CSF HVA and 5-HIAA in schizophrenia. Am J Psychiatry 1991;148:1189-1194.

33. Houston JP, Maas JW, Bowden CL, Contreras SA, Mclntyre KL, Javors MA. Cerebrospinal fluid HVA, central brain atrophy, and clinical state in schizophrenia. Psychiatry Res 1986;19: 207-214.

34. Jennings WS Jr, Schulz SC, Narasimhachari N, Hamer RM, Friedel RO. Brain ventricular size and CSF monoamine metabolites in an adolescent inpatient population. Psychiatry Res 1985; 16:87-94.

35. Post RM, Goodwin FK. Time-dependent effects of phenothiazines on dopamine turnover in psychiatric patients. Science 1975; 190:488-489.

36. Anand I, Sunitha TA, Khanna S. CSf amines and their metabolites in first episode drug naive schizophrenic patients and their correlations with dimensions of schizophrenia. Indian J Psychiatry 2002;44:212-219.

37. Neider D, Lindström LH, Bodén R. Risk factors for suicide among patients with schizophrenia: a cohort study focused on cerebrospinal fluid levels of homovanillic acid and 5-hydroxyindoleacetic acid. Neuropsychiatr Dis Treat 2016;12: 1711-1714.

38. Pickar D, Owen RR, Litman RE, Konicki E, Gutierrez R, 
Rapaport MH. Clinical and biologic response to clozapine in patients with schizophrenia. Crossover comparison with fluphenazine. Arch Gen Psychiatry 1992;49:345-353.

39. Szymanski S, Lieberman J, Pollack S, Munne R, Safferman A, Kane J, et al. The dopamine-serotonin relationship in clozapine response. Psychopharmacology (Berl) 1993;112(1 Suppl): S85-S89.

40. Risch SC, Lewine RR. Low cerebrospinal fluid homovanillic acid-5-hydroxyindoleacetic acid ratio predicts clozapine efficacy: a replication. Arch Gen Psychiatry 1993;50:670.

41. Samanaite R, Gillespie A, Sendt KV, McQueen G, MacCabe $\mathrm{JH}$, Egerton A. Biological predictors of clozapine response: a systematic review. Front Psychiatry 2018;9:327.

42. Kahn RS, Davidson M, Knott P, Stern RG, Apter S, Davis KL. Effect of neuroleptic medication on cerebrospinal fluid monoamine metabolite concentrations in schizophrenia. Serotonindopamine interactions as a target for treatment. Arch Gen Psychiatry 1993;50:599-605.

43. Sharma RP, Javaid JI, Janicak PG, Davis JM, Faull K. Homovanillic acid in the cerebrospinal fluid: patterns of response after four weeks of neuroleptic treatment. Biol Psychiatry 1993;34:128134.

44. Nikisch G, Baumann P, Wiedemann G, Kiessling B, Weisser $\mathrm{H}$, Hertel A, et al. Quetiapine and norquetiapine in plasma and cerebrospinal fluid of schizophrenic patients treated with quetiapine: correlations to clinical outcome and HVA, 5-HIAA, and MHPG in CSF. J Clin Psychopharmacol 2010;30:496503.

45. Schwarcz R, Rassoulpour A, Wu HQ, Medoff D, Tamminga CA, Roberts RC. Increased cortical kynurenate content in schizophrenia. Biol Psychiatry 2001;50:521-530.

46. Erhardt S, Blennow K, Nordin C, Skogh E, Lindström LH, Engberg G. Kynurenic acid levels are elevated in the cerebrospinal fluid of patients with schizophrenia. Neurosci Lett 2001;313:96-98.

47. Nilsson LK, Linderholm KR, Engberg G, Paulson L, Blennow K, Lindström LH, et al. Elevated levels of kynurenic acid in the cerebrospinal fluid of male patients with schizophrenia. Schizophr Res 2005;80:315-322.

48. Linderholm KR, Skogh E, Olsson SK, Dahl ML, Holtze M, Engberg G, et al. Increased levels of kynurenine and kynurenic acid in the CSF of patients with schizophrenia. Schizophr Bull 2012;38:426-432.

49. Chang WH, Chen TY, Wu HS, Hu WH, Yeh EK. Dose-response curves of homovanillic acid in pre-frontal cortex and caudate following antipsychotic drugs: relation to clinical potencies. Psychopharmacology (Berl) 1988;95:459-462.

50. Stawarz RJ, Hill H, Robinson SE, Setler P, Dingell JV, Sulser F. On the significance of the increase in homovanillic acid (HVA) caused by antipsychotic drugs in corpus striatum and limbic forebrain. Psychopharmacologia 1975:43:125-130.

51. Pugsley TA, Merker J, Lippman W. Effect of structural analogs of butaclamol (a new antipsychotic drug) on striatal homo- vanillic acid and adenyl cyclase of olfactory tubercle in rats. Can J Physiol Pharmacol 1976;54:510-515.

52. Wiesel FA, Sedvall G. Effect of antipsychotic drugs on homovanillic acid levels in striatum and olfactory tubercle of the rat. Eur J Pharmacol 1975;30:364-367.

53. Bowers MB Jr, Rozitis A. Dopamine metabolites and catalepsy after lithium and haloperidol. Eur J Pharmacol 1982;78:113115.

54. Rastogi RB, Singhal RL, Lapierre YD. Comparative effects of short- and long-term treatment with neuroleptics on behavioural activity as well as dopamine turnover in striatum. Gen Pharmacol 1982;13:35-40.

55. Scatton B, Dedek J, Korf J. Effect of sing/e and repeated administration of haloperidol and sulpiride on striatal and retinal dopamine turnover in the rat. Brain Res 1977;135:374-377.

56. Bowers MB Jr. Homovanillic acid in caudate and pre-frontal cortex following neuroleptics. Eur J Pharmacol 1984;99:103105.

57. Bowers MB Jr, Hoffman FJ Jr. Homovanillic acid in caudate and pre-frontal cortex following acute and chronic neuroleptic administration. Psychopharmacology (Berl) 1986;88: 63-65.

58. Watanabe M, Hagino Y. The atypical antipsychotic sertindole enhances efflux of dopamine and its metabolites in the rat cortex and striatum. Eur J Pharmacol 1999;367:19-23.

59. Antoniou K, Bekris S, Saranti M, Stathis P, Rimikis M, Papadopoulou-Daifoti Z. The effects of antipsychotic drugs on serotonergic activity in the rat hippocampus. Eur Neuropsychopharmacol 2000;10:315-324.

60. Jordan S, Koprivica V, Dunn R, Tottori K, Kikuchi T, Altar CA. In vivo effects of aripiprazole on cortical and striatal dopaminergic and serotonergic function. Eur J Pharmacol 2004; 483:45-53.

61. Arjona AA, Zhang SX, Adamson B, Wurtman RJ. An animal model of antipsychotic-induced weight gain. Behav Brain Res 2004; 152:121-127.

62. Hernandez L, Hoebel BG. Chronic clozapine selectively decreases prefrontal cortex dopamine as shown by simultaneous cortical, accumbens, and striatal microdialysis in freely moving rats. Pharmacol Biochem Behav 1995; 52:581-589.

63. Haleem DJ, Batool F, Khan NH, Kamil N, Ali O, Saify ZS, et al. Differences in the effects of haloperidol and clozapine on brain serotonin and dopamine metabolism and on tests related to extrapyramidal functions in rats. Med Sci Monit 2002;8:BR354-BR361.

64. Clow A, Theodorou A, Jenner P, Marsden CD. Changes in rat striatal dopamine turnover and receptor activity during one years neuroleptic administration. Eur I Pharmacol 1980;63: 135-144.

65. Nicolaou NM. Acute and chronic effects of neuroleptics and acute effects of apomorphine and amphetamine on dopamine turnover in corpus striatum and substantia nigra of the rat brain. Eur J Pharmacol 1980;64:123-132. 
66. Mefford IN, Roth KA, Agren H, Barchas JD. Enhancement of dopamine metabolism in rat brain frontal cortex: a common effect of chronically administered antipsychotic drugs. Brain Res 1988;475:380-384.

67. Shannak KS, Hornykiewicz O. Brain monoamines in the rhesus monkey during long-term neuroleptic administration. Adv Biochem Psychopharmacol 1980;24:315-323.

68. Gunne LM, Häggström JE. Experimental tardive dyskinesia. J Clin Psychiatry 1985;46(4 Pt 2):48-50.

69. Bowers MB Jr, Rozitis A. Brain homovanillic acid: regional changes over time with antipsychotic drugs. Eur J Pharmacol 1976;39:109-115.

70. See RE, Chapman MA, Murray CE, Aravagiri M. Regional differences in chronic neuroleptic effects on extracellular dopamine activity. Brain Res Bull 1992;29:473-478.

71. Sedvall G, Fyrö B, Nybäck H, Wiesel FA, Wode-Helgodt B. Mass fragmentometric determination of homovanillic acid in lumbar cerebrospinal fluid of schizophrenic patients during treatment with antipsychotic drugs. J Psychiatr Res 1974;11: 75-80.

72. Rüther E, Schilkrut R, Ackenheil M, Eben E, Hippius H. Clinical and biochemical parameters during neuroleptic treatment. I. Investigations with haloperidol. Pharmakopsychiatr Neuropsychopharmakol 1976;9:33-36.

73. Wode-Helgodt B, Eneroth P, Fyrö B, Gullberg B, Sedvall G. Effect of chlorpromazine treatment on prolactin levels in cerebrospinal fluid and plasma of psychotic patients. Acta Psychiatr Scand 1977;56:280-293.

74. Doran AR, Rubinow DR, Wolkowitz OM, Roy A, Breier A, Pickar D. Fluphenazine treatment reduces CSF somatostatin in patients with schizophrenia: correlations with CSF HVA. Biol Psychiatry 1989;25:431-439.

75. Sharma R, Javaid JI, Janicak P, Faull K, Comaty J, Davis JM. Plasma and CSF HVA before and after pharmacological treatment. Psychiatry Res 1989;28:97-104.

76. Alfredsson G, Bjerkenstedt L, Edman G, Härnryd C, Oxenstierna G, Sedvall G, et al. Relationships between drug concentrations in serum and CSF, clinical effects and monoaminergic variables in schizophrenic patients treated with sulpiride or chlorpromazine. Acta Psychiatr Scand Suppl 1984;311:49-74.

77. Härnryd C, Bjerkenstedt L, Gullberg B, Oxenstierna G, Sedvall G, Wiesel FA. Time course for effects of sulpiride and chlorpromazine on monoamine metabolite and prolactin levels in cerebrospinal fluid from schizophrenic patients. Acta Psychiatr
Scand Supp/ 1984;311:75-92.

78. Scheepers FE, Gispen-de Wied CC, Westenberg HG, Kahn RS. The effect of olanzapine treatment on monoamine metabolite concentrations in the cerebrospinal fluid of schizophrenic patients. Neuropsychopharmacology 2001;25:468-475.

79. Gerlach J, Thorsen K, Fog R. Extrapyramidal reactions and amine metabolites in cerebrospinal fluid during haloperidol and clozapine treatment of schizophrenic patients. Psychopharmacologia 1975;40:341-350.

80. Bagdy G, Perényi A, Arató M, Rotstein E. Decrease of CSF dopamine, its metabolites and noradrenalin after withdrawal of chronic neuroleptic treatment in schizophrenic patients. Psychiatry Res 1984;12:177-178.

81. Perényi A, Frecska E, Bagdy G, Révai K. Changes in mental condition, hyperkinesias and biochemical parameters after withdrawal of chronic neuroleptic treatment. Acta Psychiatr Scand 1985;72:430-435.

82. Pickar D. Perspectives on a time-dependent model of neuroleptic action. Schizophr Bull 1988;14:255-268.

83. Frecska E, Perényi A, Bagdy G, Révai K. CSF dopamine turnover and positive schizophrenic symptoms after withdrawal of long-term neuroleptic treatment. Psychiatry Res 1985;16: 221-226.

84. Beuger M, van Kammen DP, Kelley ME, Yao J. Dopamine turnover in schizophrenia before and after haloperido/ withdrawal. CSF, plasma, and urine studies. Neuropsychopharmacology 1996; 15:75-86.

85. Verbeek MM, Blom AM, Wevers RA, Lagerwerf AJ, van de Geer J, Willemsen MA. Technical and biochemical factors affecting cerebrospinal fluid 5-MTHF, biopterin and neopterin concentrations. Mol Genet Metab 2008;95:127-132.

86. Cahn W, van Haren NE, Hulshoff Pol HE, Schnack HG, Caspers E, Laponder DA, et al. Brain volume changes in the first year of illness and 5-year outcome of schizophrenia. Br J Psychiatry 2006; 189:381-382.

87. Wester P, Bergström U, Eriksson A, Gezelius C, Hardy J, Winblad B. Ventricular cerebrospinal fluid monoamine transmitter and metabolite concentrations reflect human brain neurochemistry in autopsy cases. J Neurochem 1990;54:1148-1156.

88. Eklundh T, Eriksson M, Sjöberg S, Nordin C. Monoamine precursors, transmitters and metabolites in cerebrospinal fluid: a prospective study in healthy male subjects. I Psychiatr Res 1996;30:201-208. 